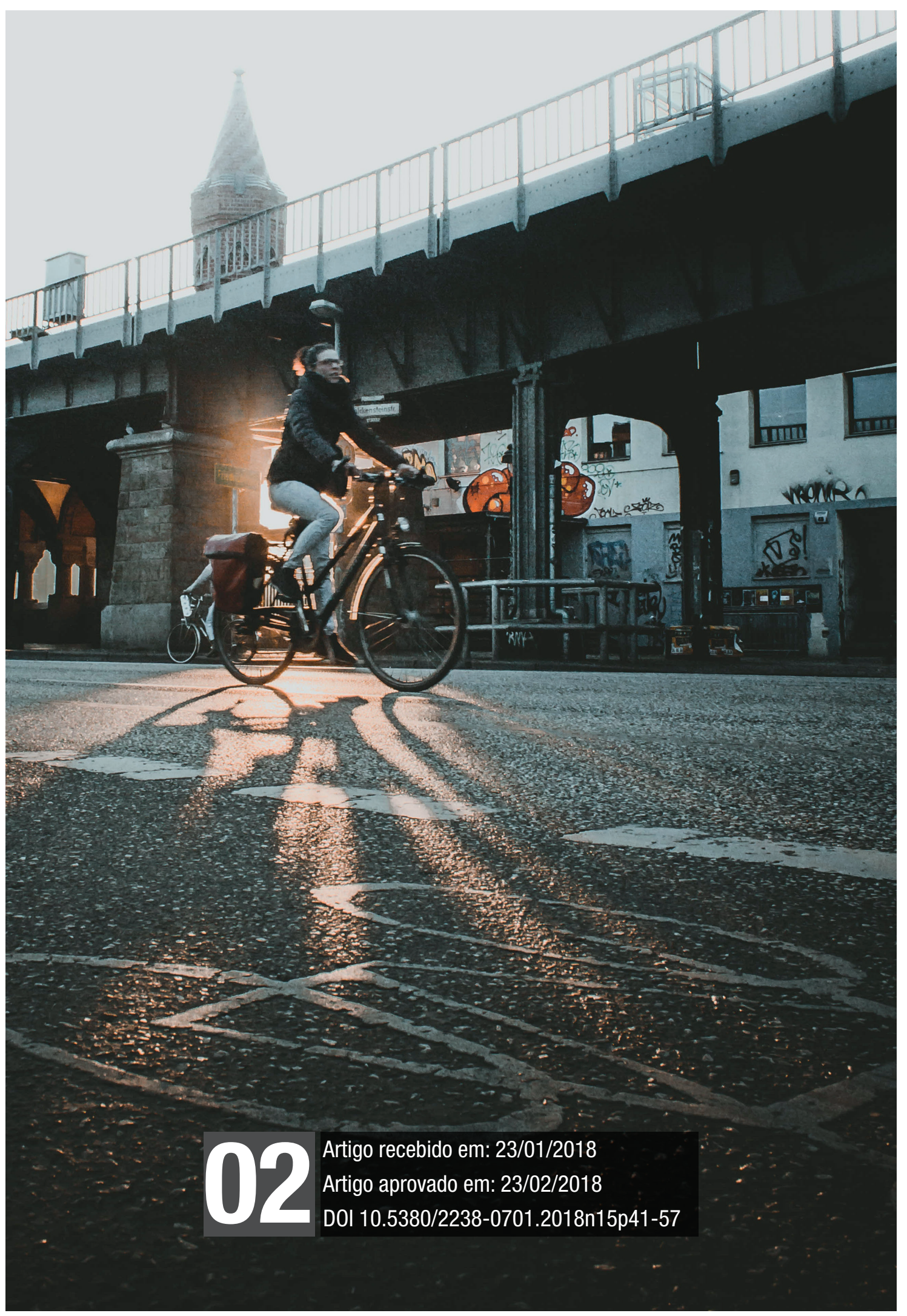


Comunicação; Mulheres; Cidade; Redes sociais; Bicicleta.

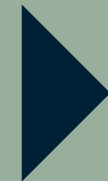




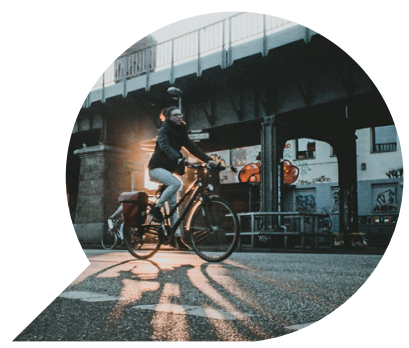

\title{
Ciclanas em rede: um estudo sobre comunicação, mulheres e espaço urbano
}

\author{
Ciclanas en red:
}

un estudio acerca de la comunicación, mujeres y espacio urbano

Ciclanas in network: a study on communication, women and urban space

ELANE ABREU DE OLIVEIRA ${ }^{1}$

PAULO VICTOR BARBOSA DE SOUSA ${ }^{2}$

Resumo: Ciclanas, coletivo ciclofeminista que atua na relação da mulher com a cidade a partir da bicicleta, é referência na cidade de Fortaleza. Buscando entender como as ferramentas de comunicação e interação auxiliam este grupo em seus propósitos, concentramo-nos em investigar o modo como ele se articula por meio do Facebook. Para esta pesquisa, realizamos uma observação direta e aplicamos questionários de perguntas abertas com mulheres que fazem parte do coletivo. Além disso, desenvolvemos uma discussão teórica sobre a relação da mulher e a cidade, bem como sobre a conexão entre redes digitais,

1 Doutora em Comunicação e Cultura pela Universidade Federal do Rio de Janeiro (UFRJ), professora do curso de Jornalismo da Universidade Federal do Cariri (UFCA).

2 Doutor em Comunicação e Cultura Contemporâneas pela Universidade Federal da Bahia (UFBA), professor efetivo do curso de Design Digital da Universidade Federal do Ceará - Campus Quixadá. 
espaço e comunicação. As respostas coletadas na pesquisa indicam uma sensação de pertencimento a uma coletividade, seja por conta das interações em rede, seja pelos encontros nas ruas, evidenciando uma produção mútua entre comunicação e espaço.

Palavras-chaves: Comunicação; Mulheres; Cidade; Redes sociais; Bicicleta.

Resumen: Ciclanas, colectivo ciclofeminista que sigue por la relación de la mujer con la ciudad a partir de la bicicleta, es referencia en la ciudad de Fortaleza. Buscando comprender cómo las herramientas de comunicación y interacción ayudan a este grupo en sus propósitos, nos hemos centrado en investigar cómo lo mismo se articula a través de Facebook. Para esta investigación, realizamos una observación directa y aplicamos cuestionarios de preguntas abiertas con mujeres que forman parte del colectivo. Además, elaboramos una discusión teórica en torno de la mujer y la ciudad, así como acerca de la conexión entre redes digitales, espacio y comunicación. Las respuestas obtenidas en la investigación indican una sensación de pertenencia a una colectividad, sea por cuenta de las interacciones en red, sea por medio de encuentros en las calles, evidenciando una producción mutua entre comunicación y espacio.

Palabras clave: Comunicación; Mujeres; Ciudad; Redes sociales; Bicicleta.

Abstract: Renowned in Fortaleza city, the feminist bike collective Ciclanas is involved in relationship between women and the city from cycling perspective. In this paper, we attempt to understand how communication and interaction tools support this group in their purposes, focusing on how it is jointed through Facebook. For this study, a direct observation was conducted into Ciclanas group, and we also applied questionnaires with open-ended questions to members. Besides, this paper presents a theoretical discussion on woman as well as the connection between digital networks, space and communication. Responses obtained in the survey denote a sense of belonging to a community, either because of their online interactivity or their meetings in the streets, stressing a mutual production between communication and space.

Key-words: Communication; Women; City; Social networks; Bike. 


\section{Introdução}

"A cidade enquanto tal não existe. Existem diferentes e distintas formas de vida urbana" (Massimo Cacciari)

O direito à cidade é contemplado por uma série de fatores e estratégias - dentre elas, a eleição e manutenção de modais de transporte. Aponta David Harvey que esse direito se dá não apenas em relação àquilo que a urbanidade oferece de estruturas, mas passa pelas oportunidades de criarmos o que entendemos e desejamos enquanto sociedade: "é o direito de mudar a nós mesmos pela mudança da cidade" (HARVEY, 2012, p. 74). Um modo de dizer que a cidade é de todos, para todos. E todas, igualmente.

Ao focar na mobilidade, o direito de "ir e vir" não é dado pelo simples trato de que a rua é pública: sua efetividade se dá na criação e manutenção de elos entre os lugares e os meios de locomoção, além do usufruto da cidade de maneira pacífica e indiscriminada. Entre variados desafios, a mobilidade e o direito à cidade, especificamente para as mulheres, é o que nos toca neste trabalho sobre o grupo Ciclanas na cidade de Fortaleza.

Espaços de expressão ainda hoje são reivindicados pelas mulheres. Daí surge a necessidade de atuações coletivas. A cidade de Fortaleza é um dos espaços cuja atuação feminina tem sido observada, e um dos seus instrumentos de poder é a bicicleta. A mulher pedalando nas ruas, exercendo sua liberdade, tem sido a motivação do grupo Ciclanas - Mulheres de Bicicleta no Trânsito de Fortaleza.

Nosso objetivo neste artigo é entender como as ferramentas de comunicação e interação auxiliam este grupo na manutenção de seus propósitos, tendo especificamente um fórum restrito no Facebook como corpus empírico. De modo geral, busca-se observar de que forma as mulheres entendem e fazem da bicicleta um instrumento de conquista da cidade a partir dessa articulação online. Partimos do pressuposto que comunicação e espacialidade são categorias inseparáveis, tendo o espaço não apenas como um "recipiente" em que ocorrem as ações sociais mas sim como objeto de contestação. Daí vem este estudo, considerando que as pessoas podem utilizar meios diversos para repensar a própria relação com o espaço, e que este mesmo possui igualmente efeitos sobre os processos comunicativos e interacionais.

A pesquisa descrita neste artigo, por meio de uma abordagem qualitativa, utiliza a observação direta assim como a aplicação de questionários 
de perguntas abertas, dos quais obtivemos a participação de oito respondentes do Ciclanas. $\mathrm{O}$ foco se dirigiu ao modo como o grupo usa redes digitais para articulação própria, propagação e discussão de questões correlatas ao empoderamento feminino quanto ao espaço urbano, buscando identificar desafios e oportunidades quanto ao uso de bicicleta como modal de transporte na cidade. O grupo serviu como um objeto de acesso e interpretação de um fenômeno mais amplo e mais complexo, que problematiza as tradicionais formas de locomoção e a delegação de espaços às mulheres. Para sustentar a análise, abordamos teoricamente a relação da mulher com a cidade, bem como a conexão entre redes digitais, espaço e comunicação. Por esse ponto de vista, pomos em questão o lugar da mulher e seu poder de mobilidade no espaço público, tendo as ferramentas de comunicação e interação atuais como mediadoras na criação de novos sentidos sobre a cidade e no fomento de articulações entre pares.

\section{A mulher e a cidade}

"Se a cidade é o mundo que o homem criou doravante ela é o mundo onde ele está condenado a viver"

(Robert Park)

Transporte, trabalho, filhos, empoderamento são termos que se misturam quando se tematizam a mulher e o uso da bicicleta. A coragem feminina de transitar nas ruas persiste sendo mote para enquadramentos midiáticos, e a luta por autonomia e pelo direito de ir e vir, em distintas regiões, é, para muitas mulheres, formas de garantir liberdade e conquista do espaço público. A rua, fisicamente, sempre esteve acessível à mulher, mas chegar à rua é diferente de fazer dela um espaço seu. A cidade não é posta para nem pela mulher. Historicamente, uma pesada carga simbólica recai sobre o usufruto do espaço público a partir da figura feminina.

$\mathrm{O}$ fato de as ruas não pertencerem às mulheres, de maneira devida e igualitária, é um índice de um domínio masculino sobre a própria cidade, enquanto a casa seria o domínio da mulher diante do poder forçoso dos homens. É o que aponta Risério (2015), ao observar, na produção literária, como os homens têm acesso à rua e como as mulheres falam de um recluso e dominado universo doméstico, tratando o espaço urbano de maneira enevoada. $\mathrm{O}$ autor aponta diferenças no modo como homens e mulheres percebem e descrevem a cidade: nos textos masculinos, a urbe é uma enti- 
dade sólida, clara, evidente; nos femininos, ela se desfaz de toda sua solidez.

O que parece permanecer, atravessando tempos, modas e estilos, é que a cidade reponta com firmeza em (e mesmo domina) textos masculinos, como no Ulysses de James Joyce, ao tempo em que quase se liquefaz, entre gazes e garoas verbais, em muitos textos femininos (RISÉRIO, 2015, p.35).

Para falar sobre a cidade, é necessário que se percorra por ela. Mas estar na rua ainda possui uma carga simbólica negativa para a mulher. A dignidade e o respeito da mulher ganham máculas quando a figura feminina se encontra no espaço urbano de forma livre, aberta e solitária. Já na Grécia Antiga, com sua democracia restrita, o acesso à cidade era diferenciado e justificado a partir do calor dos corpos, mantendo as mulheres "sérias" em casa, possibilitando-lhes um acesso à cidade de modo distinto dos homens.

A fisiologia grega justificava direitos desiguais e espaços urbanos distintos para corpos que contivessem graus de calor diferentes, o que se acentuava na fronteira entre os sexos, pois as mulheres eram tidas como versões mais frias dos homens. Elas não se mostravam nuas na cidade. Mais: permaneciam confinadas na penumbra do interior das moradas, como se isso fosse mais adequado a seus corpos do que os espaços à luz do sol (SENNETT, 1994, apud RISÉRIO, 2015, p.47)

Risério é direto: tanto quanto escrever sobre a cidade, "fazer casa e fazer cidade nunca foram coisas de mulher” (2015, p.43). Não é sem alguma ironia que a epígrafe dessa seção ressalta o homem como criador da urbe. A fundação das cidades foi uma atividade masculina, tendo a mulher papéis secundários diante dessa edificação. Algo similar ocorreu com o Brasil, por exemplo. Em 1785, dentre 124 engenhos contabilizados, apenas 10 eram propriedades de mulheres (DEL PRIORE, 2016). Ainda que o engenho não seja uma estrutura marcante da urbanidade, há de se perceber nesse dado a distância de equidade entre os gêneros na construção do país que viríamos a ter em seguida.

A função reprodutora e de cuidadora do espaço doméstico fez com que muitas outras potencialidades femininas, durante longos períodos, não fossem registradas. Suas atividades de criatividade, diversão e sexualidade, dentre outras, eram pouco toleradas e, sobre isso, a psicanalista Clarissa Estés (2014, p.17) discorre que, na geração que cresceu após a Segunda Guerra Mundial, as mulheres eram vistas como infantis e "tratadas como proprie- 
dade", tendo que "implorar pelos instrumentos e pelo espaço necessário às suas artes". A conquista por reconhecimento das liberdades femininas para além do espaço privado, da casa, é também uma luta pela compreensão de seus sentidos políticos para além dos binarismos. Dentre eles, o público-privado, que relegou à mulher o lugar "não-público", que a distancia da apropriação da cidade.

No jogo da distribuição hierárquica de lugares, as mulheres foram colocadas em subordinação, em nome da sua "natureza", dos seus atributos biológicos ou culturais, de ser, em definitiva, o não-homem, e assim, relegada ao âmbito doméstico, privado (em seu duplo sentido de carência e de não-público). (NATANSOHN, 2013, p.30)

A oposição dos mundos masculino e feminino, público e não-público, conforme a pesquisadora Graciela Natansohn (2013), deriva de um pensamento iluminista em que o homem branco e ocidental é o modelo de sujeito. Destacar as mulheres, reconhecendo-as em suas diferenças e semelhanças, leva à compreensão feminista da "categoria mulher", necessária para uni-las politicamente na busca por transformações sociais e dos discursos de subordinação. Exemplos desses discursos são ainda midiatizados, como o enunciado de capa publicado na Revista Veja, em abril de 2016, ao destacar adjetivos sobre Marcela Temer: a "bela, recatada e 'do lar". O reforço da imagem feminina vinculada ao espaço doméstico vai de encontro às possibilidades de sua atuação fora desse espaço, como a rua, o que foi motivo para gerar uma grande repercussão social da manchete, com críticas à postura da revista citada. A "natureza" privada atribuída à mulher é desnaturalizada ao passo que seu espaço político e público é reconhecido.

A luta política por direitos também se dá pela construção de coletivos em que mulheres, juntas, criam e socializam percepções e saberes. As mulheres precisaram desbravar e conquistar espaços na cultura, na sociedade, na história, na comunicação e nas cidades. Ao mesmo passo, precisam igualmente tomar os meios de comunicação e, inevitavelmente, adotar e criar suas próprias ferramentas e tecnologias digitais (NATANSOHN, 2014), o que lhes possibilitaria congregações e trocas em grupo. Coletivos de mulheres, como o Ciclanas, atuam tanto nessa tomada da voz feminina nas redes de comunicação digitais como na apropriação da cidade pelas mulheres de bicicleta. A autonomia desse coletivo é praticada nessa dupla ocupação espacial, como aponta Lucrécia Ferrara (2015): 
O encontro nas redes digitais permite superar as dificuldades de organização para criar um espaço autônomo e auto-organizável, em expansão ao mesmo tempo urbana e ciberespacial e, mais do que nunca, singular e interativo em expressão definitiva de um inalienável direito à cidade (FERRARA, 2015, p.175).

Se mudanças podem ser vistas a partir de auto-organizações (exemplos como o coletivo Não Me Kahlo e a organização Think Olga demonstram o potencial da internet para a informação sobre as causas e lutas feministas), o espaço urbano-comunicacional tem apresentado às mulheres formas de expandir suas atuações coletivas e de rua. A conquista do mercado de trabalho, a rearticulação entre público e privado, compõe a luta diária de mulheres, que ainda estão diante de estatísticas não tão animadoras. Dados de 2017 da Pesquisa Nacional por Amostra de Domicílios Contínua (PNAD Contínua) e divulgados pelo IBGE (2017) mostram que mulheres dispendem quase o dobro de horas (20,9 por semana) em trabalhos domésticos ou cuidados de pessoas quando comparadas aos homens (10,8 por semana). Ainda há muito a percorrer quanto ao fim da opressão de gênero, contudo, mulheres têm contado com novos espaços para potencializar suas vozes e seus elos comunitários. Em redes, elas ganham visibilidade e mantêm atual o propósito de viver melhor na cidade, no público, nas interações cotidianas.

\section{Redes digitais, espaço e comunicação}

O Facebook é usualmente considerado um site de rede social (SRS) e, como tal, apresenta características próprias em termos de sociabilidade e comunicação. Essa ideia de "rede social" articula um meio-termo entre a coletividade e a sua menor fração (uma pessoa), permitindo visualizações de suas redes de relacionamento. Quando no contexto da internet, o conceito de rede social diz respeito ao modo como os atores e suas informações estão dispostos e interligados entre si com a ajuda de um sistema técnico que mantém e medeia esse elo. $\mathrm{O}$ funcionamento dos SRS se dá segundo o modo nodal de relações sistematizado por Barabási (2002): de maneira simplificada, uma visualização em grafos das conexões que cada ponto daquela rede pode ter com os demais.

A definição já clássica de sites de rede social, proposta por Boyd \& Ellison (2007), é aquela que descreve um sistema eletrônico de automanutenção em que atores individuais podem criar um perfil pessoal, ligar-se a outros indivíduos e visualizar elos de outras pessoas: 
Nós definimos sites de rede social como serviços baseados na web que permitem que indivíduos (1) construam um perfil público ou semipúblico dentro de um sistema delimitado, (2) articulem uma lista de outros usuários com quem eles compartilhem uma conexão e (3) vejam e examinem suas listas de conexões, bem como as daqueles (BOYD \& ELLISSON, 2007, p. 211).

O modo como se configuram os SRS ressalta o papel preponderante de indícios de veracidade por parte dos indivíduos que compõem as redes - o que veremos adiante como ocorre no Ciclanas. Ou seja, essa é a base para o entendimento de como se formam e se caracterizam espaços próprios para as interações em rede, indo além das comunidades virtuais - notoriamente estudadas por Rheingold (1993) e muitas vezes consideradas, especialmente por visões mais apocalípticas, como mundos e territórios "apartados" da materialidade física (WELLMAN, 2011). Segundo Nancy Baym (2010), assim como o conceito de rede social representa um meio termo entre o indivíduo e sua comunidade, os sites de rede social estariam também situados em meio a duas formas de expressão e vinculação social bastante populares na internet: de um lado, as comunidades virtuais, onde a expressão mais importante é o grupo e seus interesses; e de outro, as homepages pessoais típicas do início da popularização da web e os seus sucessores blogs, que tinham no indivíduo e seu próprio arranjo de conexões a expressão primária de funcionamento.

Assim, os SRS apresentariam, a priori, uma abertura para a formatação de arranjos técnicos verificáveis e rastreáveis, em geral já baseados em laços previamente estabelecidos - o que é de grande importância para o grupo Ciclanas. Ou, nos dizeres de Boyd e Ellisson (2007, p.211),

O que faz os sites de redes sociais únicos não é que eles permitam que as pessoas se encontrem com desconhecidos, mas sim o fato de eles possibilitarem que seus usuários articulem e deixem visíveis suas redes sociais [...] Em vários dos grandes sites de redes sociais, os participantes não estão necessariamente fazendo "networking" ou procurando conhecer novas pessoas; em vez disso, eles estão primariamente se comunicando com outras pessoas que já fazem parte de sua rede social estendida.

Quando observamos a temática e a forma de atuação do Ciclanas, um simples cruzamento com os estudos mais atuais sobre comunicação, espaço e cidade não nos permite um pensamento que separe as articulações em 
rede daquilo que reverbera presencialmente. Não há mais lugar para pensar o ciberespaço apartado do que é fisicamente palpável. As visões dualistas estão superadas, e o modo como enxergamos esse caso específico em estudo nos leva a compreender que as lutas buscadas pelas Ciclanas incorporam esse duplo movimento de articulação.

Esse entendimento nos dá conta de como meios de comunicação e espaço se produzem e se modificam mutuamente (FALKHEIMER \& JANSSON, 2006; ADAMS, 2009), tanto por força das próprias condições materiais quanto devido aos enfrentamentos e às disputas de nível simbólico. Entende-se que o espaço está em meio a querelas dispostas pelas participantes do grupo, tanto discursiva quanto empiricamente, como veremos a seguir. Assim dito, a comunicação não se configura apenas como procedimento de emissões e recepções, mas uma relação de construção ou de entendimento mútuo, o que resvala na compreensão da cidade como um objeto em contestação.

\section{Estudo de caso: Fortaleza e o grupo Ciclanas}

Fortaleza, capital do Ceará, assim como boa parte das metrópoles brasileiras, apresenta vários problemas de mobilidade. Como uma possível decorrência do programa de compartilhamento de bicicletas adotado na cidade, o Bicicletar, essa modalidade ganhou notoriedade como opção de locomoção. Dados de setembro de 2015 mostram que Fortaleza teve o mais alto índice de adoção nesse tipo de projeto em todo o Brasil. Nesse cenário, grupos da sociedade civil têm reclamado ao poder público maior atenção à bicicleta como transporte. O Ciclanas é um desses coletivos e atua numa pauta específica: a relação da mulher com a cidade por meio do ciclismo voltado ao transporte.

O grupo Ciclanas se traduz como movimento "ciclofeminista": suas motivações giram em torno do uso da bicicleta no cotidiano aliado à autonomia das mulheres na cidade de Fortaleza. Surgiu no início de 2015 e são mais de 2700 mulheres que integram um grupo fechado no Facebook para discutir o uso da bicicleta e o feminismo. Ciclanas, assim, é tanto o nome dado ao grupo quanto o modo como as próprias participantes se chamam. Segundo Sheryda Lopes, jornalista e ciclana, "fora da internet, palestras, debates, pedaladas, oficinas de alongamento, mecânica para mulheres e até uma cicloviagem são algumas das ações já realizadas pelo grupo". Dessa forma, o espaço de atuação e comunicação se dá tanto pelas redes sociais online como pelos encontros presenciais que acontecem corriqueiramente. 
Vale ressaltar que, no Facebook, há tanto a página (ou fanpage), aberta para o público em geral interessado nas divulgações do coletivo, quanto o grupo restrito, cuja participação exige autorização prévia de moderadoras, voltado apenas a mulheres. Há também um perfil do coletivo no aplicativo Instagram, em que são divulgadas informações sobre eventos, imagens de incentivo ao uso da bicicleta e registros de ações realizadas. Dentre as motivações informadas no Facebook, destaca-se que o coletivo existe para "estimular mulheres que querem começar a utilizar a bicicleta no dia a dia, mas que ainda não se sentem seguras para colocar a vontade em prática" e, de uma forma mais geral, a proposta do grupo é "por uma cidade mais humana e que transforma e é transformada quando a possibilidade da bicicleta como meio de transporte é real e possível".

As Ciclanas se descrevem como um grupo sem hierarquias ou liderança centralizada - logo, em nossa pesquisa, não foi possível coletar informações de representantes ou líderes que respondessem por todo o grupo. Diante dessa máxima e sob orientação de uma das administradoras da fanpage, trabalhamos com um questionário de perguntas abertas no grupo restrito do Facebook, publicado em 25 de janeiro de 2016, o qual seria respondido por quaisquer ciclanas, sem detrimento do papel ou da posição simbólica no coletivo. Dessa forma, a priori, esperou-se que participações ocorressem de maneira mais equilibrada.

Dado o modo de destaque das publicações no grupo do Facebook, obtivemos respostas de 8 mulheres, discutidas na seção a seguir, o que dá uma leve noção sobre como a coletividade e a troca de informações naquele espaço ajudam na articulação delas. Perguntava-se sobre como a ciclana conheceu o grupo, quais suas formas de atuação e como a participação naquele grupo ajudava no enfrentamento de dificuldades e o que poderia ser feito para melhorar a condição de mobilidade feminina quanto a soluções tecnológicas. Ao final, pedíamos breves informações de identificação pessoal, como idade e ocupação.

\section{Resultados e discussão}

As respostas mostram que o Ciclanas é levado ao conhecimento de outras mulheres no "boca a boca". A rede constituída dota esse grupo de um aspecto intimista, exclusivo e protetor, o que se ressalta inclusive na forma como suas integrantes são consideradas em suas existências factuais. Dentre as respostas, uma das ciclanas se identificou como moderadora do gru- 
po, indicando que seu papel era o de aceitar ou rejeitar pedidos de entrada ali, após verificar as redes e as relações de uma requerente, a fim de checar a veracidade da pessoa: "observamos se a solicitação vem de uma mulher e que ela de fato existe, ou seja, não aceitamos homens nem perfis falsos”.

Essa forma de checagem vai ao encontro das características, dinâmicas e estruturas descritas por Boyd e Ellisson (2007) e Baym (2010), que mostraram como os sites de rede social têm um papel forte de replicação de laços prévios à própria estrutura técnica. A verificação, assim, deve estar baseada nas ligações que uma determinada pessoa possui e na forma como ela deixa rastros interativos na própria rede.

O coletivo acolhe as ciclanas a partir de problemas de mobilidade cotidianos, mas essa tônica não é o único mote de propagação. As diversas atividades realizadas pelo grupo dão conta de ações como orientação postural, oficina de manutenção de bicicleta, cicloviagens, exibição de filmes e debates. Ou seja, existe aí um sentido de troca de informações e compartilhamento de experiências coletivas que servem de acolhimento e incentivo para o uso da bicicleta, o que encoraja paulatinamente cada uma das participantes em seu objetivo: "Ainda não estou muito entrosada, mas só as dicas e o acolhimento do grupo já me ajuda tanto que não sei nem descrever. Me sinto encorajada a não desistir de pedalar independente dos apuros que eu passo todo dia", disse uma das ciclanas.

Algumas das respostas obtidas sublinham que a coletividade do Ciclanas facilita na superação dos constrangimentos do cotidiano, especialmente por haver ali uma troca constante de dicas de trajetos e compartilhamento de experiências. As respostas mostram que o grupo proporciona uma sensação de estarem juntas, o que ecoa tanto na ambiência eletrônica quanto nos deslocamentos físicos. Desse modo, as ciclanas se veem parte de uma coletividade maior, percebendo que não se encontram isoladas. Como ressalta uma das participantes da pesquisa, "conhecendo outras mulheres que também ocupam as ruas com suas bicis tem se a sensação que estamos protegidas, não estamos sós e que precisando de apoio certamente teremos, muito embora não conheçamos todas ali envolvidas".

Essa percepção se dá diante de um compartilhamento a posteriori das experiências, e não há, dentro do Ciclanas, ferramenta ou procedimento em tempo real que possa fazer com que mais mulheres se percebam nas ruas. Isso quer dizer que ainda é necessário que cada uma aposte na saída de bicicleta e que tudo correrá tranquilamente. Ainda assim, a simples "sensação" de não-isolamento já é uma importante variável a fomentar o 
ciclismo. Como relata uma das participantes da pesquisa, "sozinha eu me sentia acuada, remando contra a corrente, contra a minha família, contra a sociedade [...], então quando formamos o grupo, vi que existia uma outra forma de lidar com todas essas barreiras e consigo pedalar cada vez mais". Tal depoimento nos faz entender que o formato das comunidades virtuais não se esvaiu por conta dos SRS, mas foi incorporado por estes. Com o reconhecimento do grupo atuante em diversas camadas interativas e comunicativas (o Ciclanas usam outras plataformas de comunicação, como Whatsapp e Telegram), individualmente cada participante consegue se sentir fração de um conjunto maior.

Ainda que seja uma questão de percepção, ao se verem parte de um conjunto mais amplo, as ciclanas passam a encontrar alguma ressonância prática no dia a dia: "acho bacana poder ter possibilidade de formar grupos que vão no mesmo sentido ou para o mesmo lugar", afirma outra participante, dando a entender que a coletividade constituída no Facebook ajuda a formar grupos menores de acordo com as rotas individuais rotineiras. Outra resposta indica algo similar: "Tb o fato de conhecer mais meninas, inclusive que moram perto da minha casa, faz com que a gnt combine de ir juntas aos lugares, então me sinto muito mais segura".

Quanto às dificuldades descritas, a maioria ressalta as "finas", quando motoristas de carros ou de ônibus andam muito próximo às ciclistas: "Passei por algumas situações em relação aos condutores de carros que não respeitam e não aceitar o fato de que os ciclistas possuem direito de circular pela via pública", diz uma respondente. Outra resposta chega a ressaltar uma correlação com o tamanho dos automóveis: "Sou fechada todo tempo o tempo todo por carros e motos. E quando são transportes maiores como hilux, ônibus e afins é ainda pior".

Além disso, existem situações recorrentes de assédio moral, com gritos, piadas machistas e insinuações sexuais em geral: "vez ou outra um machista grita do carro para chamar atenção", exemplifica uma participante. A insegurança também é posta como um problema, e algumas das ciclanas chegaram a dizer que, no atual momento da cidade, já há um olhar de menor estranhamento quanto ao ciclismo: "agora as pessoas encaram com mais naturalidade", afirma uma delas, enquanto outra considera que "a educação dos fortalezenses tem mudado bastante depois da implantação das bikes compartilhadas".

Curiosamente, a especificidade da condição feminina de bicicleta foi poucas vezes ressaltada. Uma das respostas evidencia uma provável distin- 
ção de gênero no tratamento por parte de mecânicos e lojas, falando que "as meninas compartilham muitas experiências no grupo e dão dicas de onde comprar coisas mais baratas e não ser enganada por mecânicos”. Outra ciclana, quando questionada como o grupo é útil, disse haver auxílios diversos, "várias dicas, inclusive de estilo, maquiagem, etc." A resposta nos leva a entender que, tanto quanto em qualquer outra situação, há desejo não apenas por segurança e respeito, mas também por cuidados do corpo, chamando a atenção de que esse tipo de deslocamento não prescreve uma vestimenta em especial.

Ao questionarmos o que poderia ser feito em termos tecnológicos para facilitar ou melhorar a mobilidade feminina, algumas das respostas evidenciam recursos simples, como sinalizações e mapas específicos - um indício de que a sinalização urbana não é feita para pedestres ou ciclistas. Em termos de recursos digitais em rede, as plataformas já utilizadas pelas ciclanas parecem atender a suas demandas. Apenas uma participante citou um aplicativo como nova tecnologia a servir para a melhoria da mobilidade das mulheres, mas não disse como funcionaria ou o que ele teria de específico. De maneira geral, contudo, foi apontado em outra resposta que muito ainda é necessário a ser feito, "mas não exclusivamente ou especificamente para mulheres”. A inquietação da participante indica, assim, que o problema de mobilidade envolvendo gêneros necessita de um olhar amplo.

\section{Conclusão}

As respostas obtidas junto às ciclanas nos levam à compreensão de que a simples participação no grupo do Facebook já lhes apresenta uma sensação de não-isolamento, o que as leva a compreender que não estão sozinhas em deslocamentos diários. Existe nessa atuação por meio das TICs um exemplo claro de coletividade, apesar de possíveis desentendimentos pontuais, especialmente por elas se verem em torno de um objetivo em comum - usar a bicicleta como meio de transporte na cidade, não para diversão ou exercício. Essa consideração questiona o lugar da mulher na sociedade e as possibilidades de ela habitar o espaço público da maneira desejada.

Também, por meio do que se declarou nas respostas das participantes, percebe-se que a "categoria mulher" se une à categoria ciclista em nome de transformações quanto ao direito à cidade, sendo cada ciclana uma potencial representante do desejo de uma Fortaleza mais livre e sem opressão. Pedalar é também um exercício de autonomia e isso, como apontado, tem 
sido uma busca das mulheres não só nos seus deslocamentos diários, mas também no trabalho, quando passam a se desligar de um papel de gênero tradicional. Acompanhando a ideia de que o espaço doméstico deixou de ser o único cabível às atividades femininas, mover-se na cidade, como propõe o Ciclanas, torna-se também um ato cotidiano de visibilidade pública e política.

Há, subjacente a essa discussão, um questionamento sobre como os esforços coletivos podem auxiliar na constituição de um imaginário mais propício à circulação da mulher no espaço público e, indo mais a fundo, como a mulher pode ter plenos domínios de criação e gerenciamento urbano. $\mathrm{O}$ grupo Ciclanas no Facebook é um passo importante para a consolidação de direitos equalizados, mas a busca não se encerra aí. Algumas das participantes ressaltam que ainda são necessários vários equipamentos e soluções que melhorem a relação da mulher com a cidade, mas várias dessas soluções não se dirigem a um gênero único e sim com a possibilidade de locomoção adequada em geral: "A mobilidade não tem a ver com feminina ou masculina, ela precisa ser melhorada para os dois gêneros se beneficiarem", ressalta uma das ciclanas. Ainda que compreendamos gêneros para além dos binarismos, a declaração evidencia a preocupação de perceber mulheres ciclistas em diálogo com as diferenças e não em isolamento.

\section{REFERÊNCIAS}

ADAMS, Paul C. Geographies of media and communication: a critical introduction. United Kingdon: Wiley-Blackwell, 2009.

BARABÁSI, Albert-Lászlo. Linked: The New Science of Networks. Cambridge, Massachusetts: Perseus Publishing, 2002.

BAYM, Nancy K. Personal Connections in the Digital Age. Malden: Polity Press, 2010.

BOYD, Danah; ELLISON, Nicole. Social network sites: Definition, history, and scholarship. Journal of Computer-Mediated Communication, v. 13, n.1, 2007.

DEL PRIORE, Mary. Histórias da gente brasileira: v1 - Colônia. São Paulo: LeYa, 2016.

ESTÉS, Clarissa. Mulheres que correm com os lobos: mitos e histórias do arquétipo da mulher selvagem. Trad. Waldéa Barcellos. Rio de Janeiro: Rocco, 2014. 
FALKHEIMER, Jesper; JANSSON, André (ed.). Geographies of Communication: The Spatial Turn in Media Studies. Göterborg: Nordicom, 2006.

FERRARA, Lucrécia. Comunicação, mediações e interações. São Paulo: Paulus, 2015. HARVEY, David. O direito à cidade. Lutas Sociais, São Paulo, n.29, jul/dez 2012, pp.73-89.

IBGE. Diretoria de Pesquisas, Coordenação de Trabalho e Rendimento. Pesquisa Nacional por Amostra de Domicílios Contínua: outras formas de trabalho, 2017. Rio de Janeiro, 2017.

NATANSOHN, Graciela. Internet em código feminino: teorias e práticas. Ciudad Autónoma de Buenos Aires: La Crujía, 2013.

NATANSOHN, Graciela. Mulheres e uso das TIC, algumas reflexões metodológicas. In: Intercom - Sociedade Brasileira de Estudos Interdisciplinares da Comunicação. XXXVII Congresso Brasileiro de Ciências da Comunicação - Foz do Iguaçu: PR, 2014.

RHEINGOLD, Howard. The Virtual Community. New York: HarperPerennial, 1993. RISÉRIO, Antonio. Mulher, casa e cidade. Rio de Janeiro: Ed. 34, 2015.

SENNETT, Richard. Flesh and Stone: The Body and The City in Western Civilization. Nova York: W. W. Norton, 1994.

WELLMAN, Berry. Studying the Internet Through the Ages. In: CONSALVO, Mia; ESS, Charles. The Handbook of Internet Studies. Blackwell Publishing, 2011, pp. 1723 